\title{
Illness cognitions in head and neck squamous cell carcinoma: predicting quality of life outcome
}

\author{
Margreet Scharloo • Robert J. Baatenburg de Jong • \\ Ton P. M. Langeveld • Els van Velzen-Verkaik • \\ Margreet M. Doorn-op den Akker • Adrian A. Kaptein
}

Received: 3 February 2009 / Accepted: 13 August 2009/Published online: 29 August 2009

(C) The Author(s) 2009. This article is published with open access at Springerlink.com

\begin{abstract}
Goals of work This paper presents an observational study of the longitudinal effects of cancer treatment on quality of life $(\mathrm{QoL})$ in patients treated for head and neck squamous cell carcinoma (HNSCC), and evaluated the contribution of patients' baseline illness cognitions to the prediction of QoL 2 years after diagnosis.

Patients and methods One hundred seventy-seven patients eligible for primary treatment for HNSCC completed the Illness Perception Questionnaire-Revised at baseline and the European Organization for Research and Treatment of Cancer Core Quality of Life Questionnaire-30 at baseline, at 1-year and 2-year follow-ups.

Main results Compared to baseline, patients reported better emotional functioning at both follow-ups $(p<0.001)$, worse social functioning at 12 months $(p<0.05)$, and better global
\end{abstract}

\footnotetext{
M. Scharloo $(\bowtie) \cdot$ A. A. Kaptein

Medical Psychology, Leiden University Medical Center, P.O. Box 9555, 2300 RB Leiden, The Netherlands

e-mail: m.scharloo@lumc.nl
}

R. J. B. de Jong • T. P. M. Langeveld • E. van Velzen-Verkaik •

M. M. D.-o. den Akker

Department of ENT and Head and Neck Surgery,

Leiden University Medical Center,

P.O. Box 9600, 2300 RC Leiden, The Netherlands

\section{R. J. B. de Jong}

Department of Otorhinolaryngology and Head and Neck surgery,

Erasmus Medical Center,

P.O. Box 2040, 3000 CA Rotterdam, The Netherlands

\section{M. D.-o. den Akker}

Department of Dermatology and Allergology,

University Medical Center Utrecht,

Heidelberglaan 100,

3584 CX Utrecht, The Netherlands health status at 24 months $(p<0.05)$. Patients' own implicit common sense beliefs about their illness added small but significant amounts of variance to the prediction of QoL after 2 years. Less belief in own behavior causing the illness predicted better functioning and better global health. Strong illness identity beliefs predicted worse functioning and worse global health. Negative perceptions about the duration of the illness (chronic timeline beliefs) and more negative perceived consequences also predicted worse QoL.

Conclusions Our results on the negative perceptions about the duration of the illness, perceived consequences, and high symptom awareness predicting worse QoL illustrate the detrimental effects of uncertainty and negative expectations about the future course of the illness. The identification of these cognitive factors provides possible targets for counseling strategies to assist patients in long-term adjustment to HNSCC.

Keywords Head and neck cancer - Oral oncology ·

Illness cognitions · Quality of life .

Fear of recurrence (FoR) management

\section{Introduction}

Over more than 40 years, a variety of individual and groupbased psychosocial interventions has been developed specifically for people with cancer. Although the findings of several meta-analyses and research reviews have suggested the overall usefulness of psychosocial interventions for enhancing coping and improving quality of life $(\mathrm{QoL})$ in adult cancer patients [1-4], other researchers have concluded their reviews with a more pessimistic assessment that the evidence on efficacy is inconclusive at best $[5,6]$. 
One of the suggestions to shed light on these mixed conclusions regarding effectiveness of psychosocial interventions is to study potential moderators of intervention efficacy, such as cancer type, interventionist, and type of intervention [7, 8]. With regard to type of intervention, results from meta-analyses studying the efficacy of various components of interventions show that those with a greater number of components related to social cognitive theory (self-efficacy beliefs, information processing, and expectations regarding outcome and self-regulation, i.e., the process of planning, monitoring, and changing one's behaviors and cognitions) predicted better short- and/or long-term QoL outcomes for cancer patients than do interventions lacking those components [3,9].

Another suggested approach is to evaluate whether psychological process-level variables (e.g., self-esteem, perceived control) contribute to the outcome through mediating and/or moderating effects [10]. With respect to cognitive factors, studies identifying potential mechanisms by which interventions in cancer care may exert their effects on QoL are few. Only one intervention study tested whether a cognitive behavioral intervention modified cognitive factors (perceived stress management skills), and whether improvement in QoL was mediated by greater perceived skills [11]. Other studies suggested cognitive factors such as: fear of recurrence [12, 13], belief in curability [14], recovery expectations [15-17], cognitive appraisal of cancer threat [18], and patients' perceptions of their illness and treatment [19-21].

Although there has been minimal research into effective psychosocial intervention programs specifically for head and neck cancer patients, there is evidence to indicate that psychosocial interventions focusing on monitoring and altering cancer-relevant cognitions, emotions, and behaviors also have a positive effect in enhancing QoL in these patients [22-26].

Our study aims to identify specific cognitions that are (un)helpful in longer term adjustment to head and neck squamous cell carcinoma (HNSCC) as a useful step toward designing interventions for HNSCC patients. The selfregulation model (SRM) of Leventhal et al. [27] was adopted as a general conceptual framework for identifying the subjective cognitions (ideas, views, and beliefs) and emotional responses generated by the illness that contribute to adjustment after cancer treatment. According to the SRM, patients will form commonsense representations when presented with information that constitutes a threat to health, integrating internal and external stimulus information with their own preexisting illness theory. The SRM identifies two simultaneous processes-i.e., cognitive and affective - that make independent and potentially interactive contributions to health and illness behavior [28]. The model posits that the cognitive representations are concep- tualized by patients along five core dimensions: beliefs about the illness' identity (beliefs about the disease label and the symptoms associated with the illness), possible cause (beliefs about how one gets the disease), timeline of the illness (beliefs about the likely duration of illness and its expected course), controllability (beliefs about which strategies can cure/control the illness), and consequences (the perceived severity and beliefs about the physical, social, economic, and emotional effects of the illness). Preliminary support for the use of this model for explaining changes in health behavior and QoL in cancer patients comes from studies in patients with breast cancer [29-32] and patients with head and neck cancer [33].

Our specific objectives were to extend our prior research in this area, in which we demonstrated that illness cognitions were significantly related to pretreatment QoL [21], by analyzing longitudinal data, determining relationships between baseline illness cognitions, and QoL outcome 2 years after diagnosis.

\section{Patients and methods}

\section{Study population}

This is a prospective observational study, in which the study population consisted of all incident patients with head and neck squamous cell carcinoma who were diagnosed at the Department of Otolaryngology and Head and Neck Surgery at the Leiden University Medical Center, The Netherlands, between March 2002 and August 2005. Patients were followed-up until death or 2 years after diagnosis.

Patients were included if they were eligible for primary treatment for squamous cell carcinomas in the pharynx, larynx, oral cavity, nose, sinuses, esophagus, or salivary glands. Patients who were mentally retarded, demented, or unable to fill in the questionnaires for other reasons were excluded.

One hundred seventy-seven patients meeting study criteria were enrolled. The characteristics of the study sample are depicted in Table 1.

\section{Procedure}

Patients were invited to participate by a research nurse on the day of diagnostic testing. All patients were informed on the purpose of the study. The study was exempted from institutional review board approval because the questionnaires were administered as part of standard clinical care to assist treatment planning. For baseline assessment consenting, patients were handed a questionnaire packet, and they completed the questionnaires while waiting for the next diagnostic procedure, with the research nurse available to respond to questions. For follow-up measurements, patients 
Table 1 Demographic, treatment, and tumor-related characteristics of the study population

\begin{tabular}{|c|c|c|c|c|}
\hline & At baseline $(n=177)$ & Dead $(n=53)$ & Missing $(n=29)$ & Final sample $(n=95)$ \\
\hline \multicolumn{5}{|l|}{ Age (year) } \\
\hline Mean (SD) & $59.5(11.3)$ & $62.1(11.8)$ & $54.1(10.1)$ & $59.6(10.8)$ \\
\hline Range & $28-84$ & $40-84$ & $28-70$ & $36-84$ \\
\hline \multicolumn{5}{|l|}{ Gender $(n)$} \\
\hline Male & 131 & 41 & 18 & 72 \\
\hline Female & 46 & 12 & 11 & 23 \\
\hline \multicolumn{5}{|l|}{ Treatment $(n)$} \\
\hline None & 4 & 2 & - & 2 \\
\hline Irradiation only & 72 & 23 & 14 & 35 \\
\hline Surgery and irradiation & 42 & 11 & 10 & 20 \\
\hline Surgery only & 39 & 8 & 4 & 27 \\
\hline Chemotherapy only or combination with chemotherapy & 20 & 9 & 1 & 11 \\
\hline \multicolumn{5}{|l|}{ Tumor (sub)sites $(n)$} \\
\hline \multicolumn{5}{|l|}{ Pharynx } \\
\hline Nasopharynx & 10 & 4 & 1 & 5 \\
\hline Oropharynx & 46 & 15 & 8 & 23 \\
\hline Hypopharynx & 18 & 9 & 2 & 7 \\
\hline Larynx & 42 & 10 & 7 & 25 \\
\hline Oral cavity & 38 & 8 & 9 & 21 \\
\hline Other & 23 & 7 & 2 & 14 \\
\hline \multicolumn{5}{|l|}{ Tumor stage $(n)$} \\
\hline $\mathrm{T} 0$ & 4 & 1 & - & 3 \\
\hline $\mathrm{T} 1$ & 32 & 3 & 2 & 27 \\
\hline $\mathrm{T} 2$ & 51 & 13 & 15 & 23 \\
\hline $\mathrm{T} 3$ & 37 & 12 & 5 & 20 \\
\hline $\mathrm{T} 4$ & 44 & 18 & 6 & 20 \\
\hline $\mathrm{T} x$ & 9 & 6 & 1 & 2 \\
\hline \multicolumn{5}{|l|}{ Nodal stage $(n)$} \\
\hline N0 & 90 & 20 & 15 & 55 \\
\hline N1 & 21 & 3 & 6 & 12 \\
\hline $\mathrm{N} 2$ & 49 & 21 & 5 & 23 \\
\hline N3 & 8 & 4 & 1 & 3 \\
\hline $\mathrm{N} x$ & 9 & 5 & 2 & 2 \\
\hline \multicolumn{5}{|l|}{ Distant metastasis $(n)$} \\
\hline M0 & 160 & 42 & 28 & 90 \\
\hline M1 & 6 & 5 & - & 1 \\
\hline $\mathrm{M} x$ & 11 & 6 & 1 & 4 \\
\hline \multicolumn{5}{|l|}{ AJCC/UICC tumor stage $(n)$} \\
\hline I & 27 & 2 & 1 & 24 \\
\hline II & 29 & 8 & 9 & 12 \\
\hline III & 34 & 6 & 8 & 20 \\
\hline IV & 80 & 33 & 10 & 37 \\
\hline Unknown & 7 & 4 & 1 & 2 \\
\hline \multicolumn{5}{|l|}{ Prior malignancy $(n)$} \\
\hline No & 162 & 45 & 28 & 89 \\
\hline Yes & 15 & 8 & 1 & 6 \\
\hline
\end{tabular}


received a questionnaire packet by mail. Upon completion, the packet was returned to the research nurse by mail, or handed in by the patient at their follow-up visit.

\section{Measurement}

The Illness Perception Questionnaire-Revised (IPQ-R) [34] was used to measure patients' cognitive and emotional representations of their illness. The first part of the questionnaire measures the illness identity dimension with a list of 14 commonly occurring symptoms: pain, sore throat, nausea, breathlessness, weight loss, fatigue, stiff joints, sore eyes, wheezinass, headaches, upset stomach, sleep difficulties, dizziness, and loss of strength. Patients are asked to rate whether or not they have experienced each symptom since their illness, and if they believe the symptom to be specifically related to their illness (yes or no). The summed yes-rated items on the second question form the illness identity scale, with higher scores indicating a stronger belief that the experienced symptoms are part of the patient's illness.

The second part of the IPQ-R consists of 38 statements using five-point Likert scale (range "strongly agree" to "strongly disagree") and provides separate scores for the consequences, timeline (divided into the subscales: cyclical timeline and acute/chronic timeline), control (divided into the subscales: personal control and treatment control), illness coherence, and emotional representations scales. High scores indicate stronger beliefs in: serious consequences of the disease, a chronic long-term disease, illness and/ or symptoms as cyclical in nature, the patients' own ability to control symptoms, and the effectiveness of treatment in controlling the illness. Higher scores on the illness coherence scale indicate a higher degree to which patients feel they have a coherent model of the illness, and higher scores on the emotional representations scale indicate a stronger emotional response to illness.

The third part, questions about causal attributions, uses the same five-point scale and consists of 18 items. Only the causal attributions that were endorsed by more than $20 \%$ of this patient group ("chance", "smoking", "own behavior", "alcohol", and "stress") were included in further analyses. Since "smoking", "alcohol" and "own behavior" were highly correlated (Pearson correlation $>0.50, p<0.000$ ), these items were summed together to form the "own behavior" subscale. Higher scores indicate stronger beliefs in own behavior, chance, or stress causing the illness. Means ( \pm standard deviation (SD)) and reliability coefficients (Cronbach's $\alpha$ ) for the IPQ-R scales are shown in Table 2. Reliability coefficients ranged from 0.70 to 0.92 , indicating satisfactory internal consistency.

The European Organization for Research and Treatment of Cancer Core Quality of Life Questionnaire 30 (EORTC QLQ-30; version 3) [35] was used to measure quality of life. It consists of 30 items, yielding nine summary scales: physical functioning, role functioning, emotional functioning, social functioning, cognitive functioning, global health status, fatigue, pain, and nausea, and six single items. With the exception of the global health status items, patients respond on four-point Likert scale (difficulties during the last week, range "not at all" to "very much"). Global quality of life is rated on a seven-point visual analog scale (health and quality of life during the last week, range "very poor" to "excellent"). Higher scores for functional scales and global health status represent a high level of functioning/quality of life, whereas high scores for symptoms represent high levels of impairment. The scales and single items of the QLQ-C30 were scored and transformed to scales of 0 to 100 according to the EORTC Quality of Life Study Group scoring guidelines.
Table 2 Mean scores (SD) and internal reliability scores (Cronbach's $\alpha$ ) of the Illness Perception QuestionnaireRevised (IPQ-R) scales

\begin{tabular}{lcc}
\hline Scales IPQ-R & Mean (SD) & Cronbach's $\alpha$ \\
\hline Illness identity & $2.61(2.62)$ & 0.79 \\
Consequences & $19.11(4.40)$ & 0.76 \\
Timeline & & \\
Cyclical & $9.68(2.96)$ & 0.70 \\
Acute/chronic & $17.12(4.45)$ & 0.86 \\
Control & & \\
Personal & $18.33(3.51)$ & 0.74 \\
Treatment & $17.53(3.15)$ & 0.78 \\
Illness coherence & $15.78(4.05)$ & 0.75 \\
Emotional representations & $18.93(6.43)$ & 0.92 \\
Causal attributions & & \\
Behavioral (alcohol, smoking, my own behavior) & $8.28(3.20)$ & 0.80 \\
Chance & $3.28(1.22)$ & - \\
Stress & $2.35(1.19)$ & - \\
\hline
\end{tabular}


Statistical analysis

All data were analyzed using the Statistical Package for the Social Sciences (SPSS 14.0 for Windows). The significance of differences between patients who completed measurements and those who died or dropped out was tested using chi-square statistics and Student's $t$ test. Descriptive means, standard deviations, and Cronbach's alpha for the IPQ-R subscales were calculated at baseline. A one-way repeated measures analysis of variance was conducted to explore changes in QLQ-C30 functioning and global health status scales at diagnosis, at 12 months and 24 months follow-ups. Multiple regressions were used to examine if baseline illness perceptions explained variance on QLQ-C30 functioning and global health status scales 2 years after diagnosis. For each QoL scale, multiple regression equations were computed. Age and American Joint Committee on Cancer (AJCC)/ International Union Against Cancer (UICC) tumor stages were force-entered on the first step, and baseline measurement of the outcome variable was force-entered on the second step to correct for the possible influence of these factors on QoL at 24 months. On the third step, a selection of the IPQ-R subscales were entered stepwise into the regressions to examine which illness perceptions explain variance independently from and on top of age, tumor stage, and baseline QoL. To limit the number of variables entered into the regressions and avoid multicollinearity, only the IPQ-R cognitive and emotional representations scales that correlated significantly with QoL at 2 years were entered.

\section{Results}

\section{Patients}

Patients were followed prospectively over 2 years. From the initial patient sample, 53 patients died before the end of the study (30\%), 29 patients withdrew (16\%), and 95 patients completed measurements at 24 months. Patients who died within study period and patients who withdrew did not differ from participants who completed on baseline QoL or illness cognitions, except for chronic timeline beliefspatients who died had higher chronic belief at baseline $(F(2,149)=6.9, p<0.001)$. With respect to demographic, treatment, and tumor-related characteristics (see Table 1), patients who withdrew differed from patients who completed on AJCC/UICC tumor stage $(\chi 2=10.3, d f=3 ; p<$ 0.05 ). Patients who withdrew were significantly less frequently diagnosed in stage I (4\% vs $26 \%)$ and more frequently in stage II ( $32 \%$ vs. $13 \%)$. Patients who died also differed from patients who completed on AJCC/UICC tumor stage $(\chi 2=9.8, d f=3 ; p<0.05)$, with the majority of patients who died being diagnosed in stage IV (62.5\%).
Quality of life over time

Scores on the QLQ-C30 functioning and global health status scales were compared across time for patients who completed measurements at 24 months (see Fig. 1). Significant effects for time were found for emotional functioning (Wilks' lambda $=0.73 ; F(2,65)=11.84, p<0.001)$, social functioning (Wilks' lambda $=0.90 ; F(2,65)=3.52, p<0.05$ ), and global health status (Wilks' lambda $=0.90 ; F(2,62)=3.44, p<0.05$ ), with significantly better emotional functioning at 12 and 24 months as compared to baseline $(p<0.001)$, social functioning being worse at 12 months $(p<0.05)$, but not significantly different from baseline at 24 months $(p=0.06)$, and better global health status scores at 24 months as compared to baseline $(p<0.05)$.

Predicting quality of life

As evident in Table 3, tests of the significance of the variables in the equations revealed that age and AJCC/ UICC tumor stages (step 1) did not significantly contribute to the variance in any of the QLQ-C30 scales at 24 months postdiagnosis. With the exception of role functioning, baseline QLQ-C30 functioning (step 2) explained most of the variance in functioning $(47 \%, 42 \%, 26 \%$, and $64 \%$ in physical, emotional, social, and cognitive functioning, respectively) and in global health (31\%). Better baseline functioning predicted better functioning at 24 months.

When we examine the additional variance explained by baseline illness cognitions, results show that consequences beliefs $(4 \%)$ and behavioral attributions $(3 \%)$ significantly

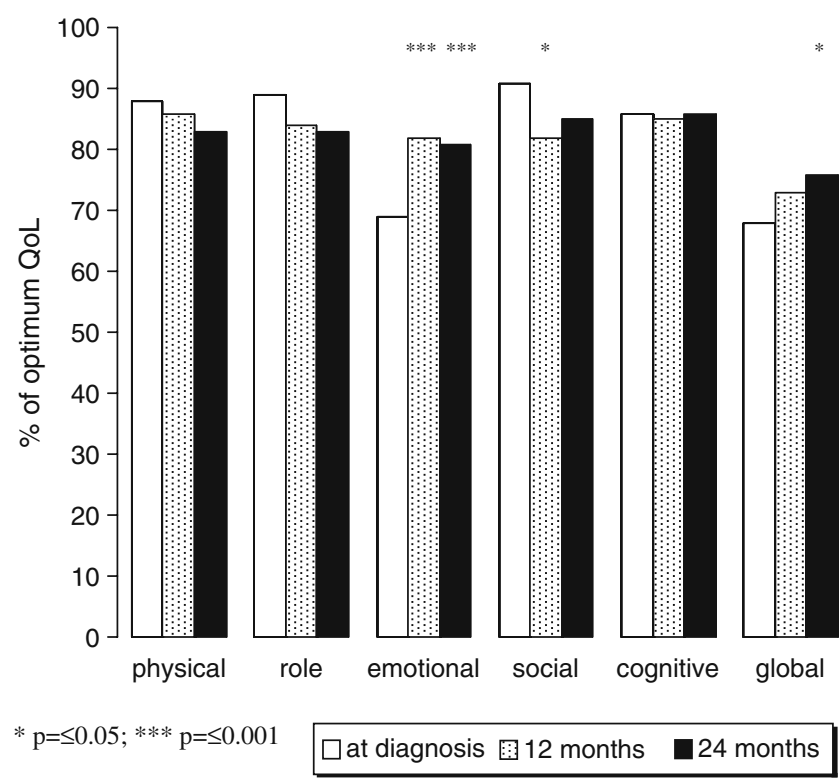

Fig. 1 Differences between QLQ-C30 functioning scales and global health scale scores at diagnosis and at follow-up (12 months and 24 months); * $p=\leq 0.05 ; * * * p=\leq 0.001$ 
Table 3 Regression analyses: percentages of variance on the QLQ-C30 functioning scales and global health scale explained by age, illness stage, functioning at baseline, and illness perceptions a Illness perceptions dimensions entered for the prediction of the QLQ-C30 functioning scales included: physical functioning: identity, consequences, and behavioral attributions; role functioning: identity, consequences, and behavioral attributions; emotional functioning: identity, consequences, emotional representations, and stress attributions; cognitive functioning: identity, timeline chronic, timeline cyclical, consequences, emotional representations, and stress attributions; social functioning: identity, timeline cyclical, consequences, illness coherence, emotional representations, behavioral attributions, stress attributions; global health: identity, timeline chronic, consequences, emotional representations, behavioral attributions, and stress attributions

NS nonsignificant

$* p<0.05 ; * * p<0.01, * * * p<$ 0.001

\begin{tabular}{|c|c|c|c|c|}
\hline Step and variable ${ }^{\mathrm{a}}$ & Beta & Summarized $\mathrm{R}^{2}(\%)$ & $\mathrm{R}^{2}$ change $(\%)$ & $F$ of change ( $p$ value) \\
\hline \multicolumn{5}{|l|}{ Physical functioning } \\
\hline 1. Age & & $3 \%$ & $3 \%$ & NS \\
\hline Illness stage & & & & \\
\hline 2. Physical functioning T1 & 0.60 & $50 \%$ & $47 \%$ & $* * *$ \\
\hline 3. Consequences & -0.19 & $54 \%$ & $4 \%$ & $*$ \\
\hline Behavioral attributions & -0.18 & $56 \%$ & $3 \%$ & $*$ \\
\hline \multicolumn{5}{|l|}{ Role functioning } \\
\hline 1. Age & & $1 \%$ & $1 \%$ & NS \\
\hline Illness stage & & & & \\
\hline 2. Role functioning $\mathrm{T} 1$ & & $9 \%$ & $8 \%$ & NS \\
\hline 3. Illness identity & -0.44 & $24 \%$ & $15 \%$ & $* * *$ \\
\hline Behavioral attributions & -0.26 & $32 \%$ & $9 \%$ & $* *$ \\
\hline Consequences & -0.22 & $36 \%$ & $4 \%$ & $*$ \\
\hline \multicolumn{5}{|l|}{ Emotional functioning } \\
\hline 1. Age & & $1 \%$ & $1 \%$ & NS \\
\hline Illness stage & & & & \\
\hline 2. Emotional functioning $\mathrm{T} 1$ & 0.65 & $42 \%$ & $42 \%$ & $* * *$ \\
\hline \multicolumn{5}{|l|}{ Social functioning } \\
\hline 1. Age & & $2 \%$ & $2 \%$ & NS \\
\hline \multicolumn{5}{|l|}{ Illness stage } \\
\hline 2. Social functioning $\mathrm{T} 1$ & 0.29 & $27 \%$ & $26 \%$ & $* * *$ \\
\hline 3. Illness identity & -0.50 & $50 \%$ & $23 \%$ & $* * *$ \\
\hline Behavioral attributions & -0.22 & $55 \%$ & $5 \%$ & $*$ \\
\hline \multicolumn{5}{|l|}{ Cognitive functioning } \\
\hline 1. Age & & $1 \%$ & $1 \%$ & NS \\
\hline Illness stage & & & & \\
\hline 2. Cognitive functioning $\mathrm{T} 1$ & 0.78 & $64 \%$ & $64 \%$ & $* * *$ \\
\hline 3. Timeline chronic & -0.15 & $67 \%$ & $2 \%$ & $*$ \\
\hline \multicolumn{5}{|l|}{ Global health } \\
\hline 1. Age & & $4 \%$ & $4 \%$ & NS \\
\hline \multicolumn{5}{|l|}{ Illness stage } \\
\hline 2. Global health $\mathrm{T} 1$ & 0.23 & $35 \%$ & $31 \%$ & $* * *$ \\
\hline 3. Illness identity & -0.39 & $48 \%$ & $14 \%$ & $* * *$ \\
\hline Behavioral attributions & -0.25 & $55 \%$ & $7 \%$ & $* *$ \\
\hline Consequences & -0.18 & $58 \%$ & $3 \%$ & $*$ \\
\hline
\end{tabular}

and uniquely added to the variance explained in QLQ-C30 physical functioning. Lower perceived consequences scores and less belief in own behavior causing the illness were associated with better physical functioning. Together with identity perceptions, behavioral attributions and perceived consequences beliefs also contributed significantly to the variance in QLQ-C30 role functioning (15\%, 9\%, and 4\%, respectively) and global health status $(14 \%, 7 \%$, and $3 \%$, respectively) with fewer perceived symptoms, less belief in own behavior causing the illness, and lower consequences scores being associated with better role functioning and higher global health status ratings. Behavioral attributions also contributed significantly to the variance in QLQ-C30 social functioning $(5 \%)$, with less belief in own behavior causing the illness being associated with better social functioning. With regard to cognitive functioning, chronic timeline perceptions added a small but significant $2 \%$ to the prediction. Belief that the illness will be permanent was associated with worse cognitive functioning.

\section{Discussion}

This paper presents an observational study of the longitudinal effects of cancer treatment on QoL in HNSCC patients, exploring the contribution of baseline illness cognitions to the prediction of QoL 2 years after diagnosis. The general findings in the present study suggest that, 
although pretreatment QoL is by far the strongest predictor of QoL at 2-year follow-up, illness cognitions add small but significant amounts of variance to the prediction, with behavioral attributions, perceived consequences, and illness identity beliefs as the most consistent predictors.

Longitudinal results from prospective studies in head and neck cancer patients show a general trend that QoL deteriorates during and directly after treatment and restores to pretreatment levels after 12 months, despite functional disabilities [36]. Studies with longer follow-up periods report no clinical significant improvements in QoL after 1 year, with physical functioning and role functioning deteriorating over time and emotional functioning and global health improving [37-39]. Findings in our sample on quality of life over time closely parallel these results.

Less belief in own behavior causing the illness was predictive of better physical, role, and social functioning and better global health in our sample. These results strengthen our previous cross-sectional findings [21] and confirm the negative effects of self-blame in cancer found by others, who reported that stronger self-blame attributions were related to more psychological distress and poorer QoL in patients with breast cancer [40-43]. Also, self-blame was found to be associated with potentially health-damaging behavior following treatment in patients with head and neck cancer [44]. Christensen et al. found that patients who attributed the cause of their cancer to their past substance use exhibited a higher likelihood of continued smoking, but only if they also reported a low degree of perceived control over their future cancer-related health. Other studies found that blaming one's past behaviors for cancer does not (automatically) enhance perceptions of control over future recovery/recurrence $[40,42,43]$ and conclude that healthcare professionals should offer support to discourage the use of self-blame.

Strong baseline illness identity beliefs predicted worse social and role functioning and worse global health after 2 years. High symptom awareness predicting distress was also found in a study by Millar et al. [29]. It is suggested that persistent vigilance to somatic signs is associated with fear of recurrence (FoR) and that even common, noncancerlike symptoms (such as tiredness and headaches) will become part of patients' illness models, thus playing a major role in evoking FoR [13, 45]. FoR can arise already before treatment [46, 47], is one of the most frequently reported concerns for many cancer patients [48], and is an important stressor in the lives of both patients and significant others [49-51]. Our results on the negative perceptions about the duration of the illness (chronic timeline beliefs) and more negative perceived consequences at baseline predicting worse $\mathrm{QoL}$ also illustrate the detrimental effects of uncertainty and negative expectations about the future course of the illness. The results are consistent with previous research in showing that the way patients conceptualize their cancer appears to be more influential in determining levels of posttreatment distress than objective indicators of the likelihood of recurrence (e.g., stage of disease) or performance status (Karnofsky status) $[15,30]$. Studies examining QoL in long-term cancer survivors have reported that uncertainty in illness extends the impact of cancer well beyond the treatment phase and has a direct negative influence on patients' QoL [12, 45, 50, 52-54]. According to the self-regulation model, patients' illness cognitions help determine their illness-related behaviors and attempts to control distress. We speculate that those who have more negative expectations about the future course of the illness may be less motivated to engage in adaptive strategies to remain well and psychologically healthy, both during and after treatment. The stronger associations between negative illness cognitions and social and role functioning in our study might indicate that these patients are less successful in organizing social support.

One of the limitations of the current study is that the sample is inherently biased toward patients who survived. Patients who remained in the study were recruited into the study with significantly earlier stage tumors, and our data are, therefore, biased toward patients with relatively less physical consequences of treatment. Also, our longitudinal design does not take into account the concerns raised by Llewellyn et al. [33] that baseline factors such as illness cognitions are likely to change over the course of the illness. Within the SRM, it is posited that illness cognitions, health-related responses, and evaluation of health outcome are recursive stages in illness trajectories, thus suggesting that studying the process of change in illness cognitions might be more appropriate than studying pretreatment beliefs as predictors of longitudinal outcomes. In our study, illness cognitions were measured in the initial stages of treatment (even before patients received their definitive diagnosis), and since, it is likely that over the course of a (very burdensome) treatment patients' beliefs will fluctuate, this might explain why baseline illness cognitions only added small amounts of variance to the prediction of follow-up QoL. From our results, however, it can also be tentatively concluded that by changing pretreatment cognitive factors, long-term functional outcome after treatment for HNSCC can be improved.

Understanding the experience of illness from the perspective of the patient provides clinically relevant information to guide intervention and treatment. In particular, when assisting patients to adjust to HNSCC, from our results, it seems that supportive care need to target patients' cognitions about own behavior causing the illness, illness identity beliefs, chronic timeline beliefs, and perceived consequences. Intervention trials addressing uncertainty and FoR underline the importance of influencing negative 
cognitions in reducing uncertainty and strengthening QoL outcome after cancer $[13,55,56]$. One intervention was especially designed to assist patients with uncertainty during watchful waiting in prostate cancer. This study documents benefits of cognitive reframing and refocusing attention to satisfying and rewarding areas of life [55].The very recently developed intervention by Humphris and Ozakinci [13] seems promising and concentrates on symptom identification and recurrence fear management, discussion of illness beliefs, and moderation of excessive checking behavior in patients with head and neck cancer. Results from intervention studies with a focus on selfregulation in other illnesses show that changing illness perceptions is possible and can result in improved functional outcome [57-59].

Conflict of interest statement None of the authors has a conflict of interest to declare in relation to this work.

Open Access This article is distributed under the terms of the Creative Commons Attribution Noncommercial License which permits any noncommercial use, distribution, and reproduction in any medium, provided the original author(s) and source are credited.

\section{References}

1. Gysels M, Higginson IJ, Rajasekaran M, Davies E, Harding R (2004) Improving supportive and palliative care for adults with cancer. National Institute for Clinical Excellence. http://www.nice. org.uk/nicemedia/pdf/csgspresearchevidence.pdf. Date accessed: 30 July 2008

2. Meyer TJ, Mark MM (1995) Effects of psychosocial interventions with adult cancer patients: a meta-analysis of randomized experiments. Health Psychol 14:101-108

3. Osborn RL, Demoncada AC, Feuerstein M (2006) Psychosocial interventions for depression, anxiety, and quality of life in cancer survivors: meta-analyses. Int J Psychiatry Med 36:13-34. doi:10.2190/EUFN-RV1K-Y3TR-FK0L

4. Rehse B, Pukrop R (2003) Effects of psychosocial interventions on quality of life in adult cancer patients: meta-analysis of 37 published controlled outcome studies. Patient Educ Counsel 50:179-186. doi:10.1016/S0738-3991(02)00149-0

5. Lepore SJ, Coyne JC (2006) Psychological interventions for distress in cancer patients: a review of reviews. Ann Behav Med 32:85-92

6. Newell SA, Sanson-Fisher WR, Salvolainen NJ (2002) Systematic review of psychological therapies for cancer patients: overview and recommendations for future research. J Natl Cancer Inst 94:558-584. doi:10.1093/jnci/94.8.558

7. Stanton AL (2006) Psychosocial concerns and interventions for cancer survivors. J Clin Oncol 24:5132-5137. doi:10.1200/ JCO.2006.06.8775

8. Zimmermann T, Heinrichs N, Baucom DH (2007) "Does one size fit all?" Moderators in psychosocial interventions for breast cancer patients: a meta-analysis. Ann Behav Med 34:225-239

9. Graves KD (2003) Social cognitive theory and cancer patients' quality of life: a meta-analysis of psychosocial intervention components. Health Psychol 22:210-219. doi:10.1037/02786133.22.2.210
10. Owen JE, Klapow JC, Hicken B, Tucker DC (2001) Psychosocial interventions for cancer: review and analysis using a three-tiered outcomes model. Psychooncology 10:218-230. doi:10.1002/ pon.509

11. Penedo FJ, Dahn JR, Molton I, Gonzalez JS, Kinsinger D, Roos BA, Carver CS, Schneiderman N, Antoni MH (2004) Cognitivebehavioral stress management improves stress-management skills and quality of life in men recovering from treatment of prostate carcinoma. Cancer 100:192-200. doi:10.1002/cncr.11894

12. Hart SL, Latini DM, Cowan JE, Carroll PR, Investigators CaPSURE (2008) Fear of recurrence, treatment satisfaction, and quality of life after radical prostatectomy for prostate cancer. Support Care Cancer 16:161-169. doi:10.1007/s00520-007-0296-x

13. Humphris G, Ozakinci G (2008) The AFTER intervention: a structured psychological approach to reduce fears of recurrence in patients with head and neck cancer. Br J Health Psychol 13:223230. doi:10.1348/135910708X283751

14. Beadle GF, Yates PM, Najman JM, Clavarino A, Thomson D, Williams G, Kenny L, Roberts S, Mason B, Schlect D (2004) Beliefs and practices of patients with advanced cancer: implications for communication. Br J Cancer 91:254-257. doi:10.1038/sj.bjc.6601950

15. Koller M, Lorenz W, Wagner K, Keil A, Trott D, EngenhartCabillic R, Nies C (2000) Expectations and quality of life of cancer patients undergoing radiotherapy. J R Soc Med 93:621-628

16. Wagner MK, Armstrong D, Laughlin JE (1995) Cognitive determinants of quality of life after onset of cancer. Psychol Rep $77: 147-154$

17. Winterling J, Glimelius B, Nordin K (2008) The importance of expectations on the recovery period after cancer treatment. Psychooncology 17:190-198. doi:10.1002/pon.1216

18. Steginga SK, Lynch BM, Hawkes A, Dunn J, Aitken J (2008) Antecedents of domain-specific quality of life after colorectal cancer. Psychooncology. doi:10.1002/pon.1388

19. Llewellyn CD, McGurk M, Weinman J (2006) Head and neck cancer: to what extent can psychological factors explain differences between health-related quality of life and individual quality of life? Br J Oral Maxillofac Surg 44:351-357. doi:10.1016/j. bjoms.2005.06.033

20. Llewellyn CD, McGurk M, Weinman J (2007) The relationship between the Patient Generated Index (PGI) and measures of HR-QoL following diagnosis with head and neck cancer: are illness and treatment perceptions determinants of judgment-based outcomes? Br J Health Psychol 12:421-437. doi:10.1348/135910706X118422

21. Scharloo M, Baatenburg de Jong RJ, Langeveld TP, van VelzenVerkaik E, Doorn-op den Akker MM, Kaptein AA (2005) Quality of life and illness perceptions in patients with recently diagnosed head and neck cancer. Head Neck 27:857-863. doi:10.1002/ hed. 20251

22. Allison PJ, Edgar L, Nicolau B, Archer J, Black M, Hier M (2004) Results of a feasibility study for a psycho-educational intervention in head and neck cancer. Psychooncology 13:482485. doi: $10.1002 /$ pon. 816

23. Hammerlid E, Persson LO, Sullivan M, Westin T (1999) Qualityof-life effects of psychosocial intervention in patients with head and neck cancer. Otolaryngol Head Neck Surg 120:507-516. doi:10.1053/hn.1999.v120.a90352

24. Semple CJ, Dunwoody L, Sullivan K, Kernohan WG (2006) Patients with head and neck cancer prefer individualized cognitive behavioural therapy. Eur J Cancer Care (Engl) 15:220-227. doi:10.1111/j.1365-2354.2005.00643.x

25. Semple CJ, Dunwoody L, Kernohan WG, McCaughan E (2008) Development and evaluation of a problem-focused psychosocial intervention for patients with head and neck cancer. Support Care Cancer. doi:10.1007/s00520-008-0480-7

26. Vilela LD, Nicolau B, Mahmud S, Edgar L, Hier M, Black M, Franco EL, Allison PJ (2006) Comparison of psychosocial 
outcomes in head and neck cancer patients receiving a coping strategies intervention and control subjects receiving no intervention. J Otolaryngol 35:88-96

27. Leventhal H, Leventhal EA, Contrada RJ (1998) Self-regulation, health, and behavior: a perceptual-cognitive approach. Psychol Health 13:717-733. doi:10.1080/08870449808407425

28. Hagger MS, Orbell S (2003) A meta-analytic review of the commonsense model of illness representations. Psychol Health 18:141-184. doi:10.1080/088704403100081321

29. Millar K, Purushotham AD, McLatchie E, George WD, Murray GD (2005) A 1-year prospective study of individual variation in distress, and illness perceptions, after treatment for breast cancer. J Psychosom Res 58:335-342. doi:10.1016/j.jpsychores.2004.10.005

30. Rabin C, Leventhal H, Goodin S (2004) Conceptualization of disease timeline predicts posttreatment distress in breast cancer patients. Health Psychol 23:407-412. doi:10.1037/0278-6133.23.4.407

31. Rabin C, Pinto B (2006) Cancer-related beliefs and health behavior change among breast cancer survivors and their firstdegree relatives. Psychooncology 15:701-712. doi:10.1002/ pon. 1000

32. Stewart DE, Cheung AM, Duff S, Wong F, McQuestion M, Cheng T, Purdy L, Bunston T (2001) Attributions of cause and recurrence in long-term breast cancer survivors. Psychooncology 10:179-183. doi:10.1002/pon.497

33. Llewellyn CD, McGurk M, Weinman J (2007) Illness and treatment beliefs in head and neck cancer: is Leventhal's commonsense model a useful framework for determining changes in outcomes over time? J Psychosom Res 63:17-26. doi:10.1016/ j.jpsychores.2007.01.013

34. Moss-Morris R, Weinman J, Petrie KJ, Horne R, Cameron LD, Buick D (2002) The revised Illness Perception Questionnaire (IPQR). Psychol Health 17:1-16. doi:10.1080/08870440290001494

35. Sherman AC, Simonton S, Adams DC, Vural E, Owens B, Hanna E (2000) Assessing quality of life in patients with head and neck cancer: cross-validation of the European Organization for Research and Treatment of Cancer (EORTC) Quality of Life Head and Neck module (QLQ-H\&N35). Arch Otolaryngol Head Neck Surg 126:459-467. doi:10.1001/archotol.126.4.459

36. Ledeboer QC, Velden LA, Boer MF, Feenstra L, Pruyn JF (2005) Physical and psychosocial correlates of head and neck cancer: an update of the literature and challenges for the future (1996-2003). Clin Otolaryngol 30:303-319

37. Abendstein H, Nordgren M, Boysen M, Jannert M, Silander E, Ahlner-Elmqvist M, Hammerlid E, Bjordal K (2005) Quality of life and head and neck cancer: a 5-year prospective study. Laryngoscope 115:2183-2192. doi:10.1097/01.MLG.0000181507.69620.14

38. Nordgren M, Hammerlid E, Bjordal K, Ahlner-Elmqvist M, Boysen M, Jannert M (2008) Quality of life in oral carcinoma: a 5-year prospective study. Head Neck 30:461-470. doi:10.1002/ hed.20735

39. Nordgren M, Jannert M, Boysen M, Ahlner-Elmqvist M, Silander E, Bjordal K, Hammerlid E (2006) Health-related quality of life in patients with pharyngeal carcinoma: a 5-year follow-up. Head Neck 28:339-349. doi:10.1002/hed.20334

40. Bennett KK, Compas BE, Beckjord E, Glinder JG (2005) Selfblame and distress among women with newly diagnosed breast cancer. J Behav Med 28:313-323. doi:10.1007/s10865-005-9000-0

41. Friedman LC, Romero C, Elledge R, Chang J, Kalidas M, Dulay MF, Lynch GR, Osborne CK (2007) Attribution of blame, selfforgiving attitude, and psychological adjustment in women with breast cancer. J Behav Med 30:351-357. doi:10.1007/s10865007-9108-5

42. Houldin AD, Jacobsen B, Lowery BJ (1996) Self-blame and adjustment to breast cancer. Oncol Nurs Forum 23:75-79
43. Malcarne VL, Compas BE, Epping-Jordan JE, Howell DC (1995) Cognitive factors in adjustment to cancer: attributions of selfblame and perceptions of control. J Behav Med 18:401-417. doi:10.1007/BF01904771

44. Christensen AJ, Moran PJ, Ehlers SL, Raichle K, Karnell L, Funk G (1999) Smoking and drinking behavior in patients with head and neck cancer: effects of behavioral self-blame and perceived control. J Behav Med 22:407-418. doi:10.1023/A:1018669222706

45. Easterling DV, Leventhal H (1989) Contribution of concrete cognition to emotion: neutral symptoms as elicitors of worry about cancer. J Appl Psychol 74:787-796

46. Llewellyn CD, Weinman J, McGurk M, Humphris G (2008) Can we predict which head and neck cancer survivors develop fears of recurrence? J Psychosom Res 65:525-532. doi:10.1016/j.jpsychores.2008.03.014

47. Mehta SS, Lubeck DP, Pasta DJ, Litwin MS (2003) Fear of cancer recurrence in patients undergoing definitive treatment for prostate cancer: results from CaPSURE. J Urol 170:1931-1933. doi:10.1097/01.ju.0000091993.73842.9b

48. Meyerowitz BE, Kurita K, D'Orazio LM (2008) The psychological and emotional fallout of cancer and its treatment. Cancer J 14:410-413. doi:10.1097/PPO.0b013e31818d8757

49. Hodges LJ, Humphris GM (2008) Fear of recurrence and psychological distress in head and neck cancer patients and their carers. Psychooncology. doi:10.1002/pon.1346 [Epub ahead of print]

50. Lasry JC, Margolese RG (1992) Fear of recurrence, breastconserving surgery, and the trade-off hypothesis. Cancer 69:2111-2115

51. Mellon S, Kershaw TS, Northouse LL, Freeman-Gibb L (2007) A family-based model to predict fear of recurrence for cancer survivors and their caregivers. Psychooncology 16:214-223. doi:10.1002/pon. 1074

52. Simard S, Savard J (2008) Fear of Cancer Recurrence Inventory: development and initial validation of a multidimensional measure of fear of cancer recurrence. Support Care Cancer. doi:10.1007/ s00520-008-0444-y

53. Wonghongkul T, Dechaprom N, Phumivichuvate L, Losawatkul S (2006) Uncertainty appraisal coping and quality of life in breast cancer survivors. Cancer Nurs 29:250-257

54. Zhao L, Portier K, Stein K, Baker F, Smith T (2009) Exploratory factor analysis of the cancer problems in living scale: a report from the American Cancer Society's Studies of Cancer Survivors. J Pain Symptom Manage 37:676-686. doi:10.1016/j.jpainsymman. 2008.04.011

55. Bailey DE, Mishel MH, Belyea M, Stewart JL, Mohler J (2004) Uncertainty intervention for watchful waiting in prostate cancer. Cancer Nurs 27:339-346

56. Gil KM, Mishel MH, Belyea M, Germino B, Porter LS, Clayton M (2006) Benefits of the uncertainty management intervention for African American and White older breast cancer survivors: 20month outcomes. Int J Behav Med 13:286-294. doi:10.1207/ s15327558ijbm1304_3

57. Fortune DG, Richards HL, Griffiths CE, Main CJ (2004) Targeting cognitive-behaviour therapy to patients' implicit model of psoriasis: results from a patient preference controlled trial. Br J Clin Psychol 43:65-82. doi:10.1348/014466504772812977

58. Petrie KJ, Cameron LD, Ellis CJ, Buick D, Weinman J (2002) Changing illness perceptions after myocardial infarction: an early intervention randomized controlled trial. Psychosom Med 64:580-586

59. Skinner TC, Carey ME, Cradock S, Daly H, Davies MJ, Doherty Y, Heller S, Khunti K, Oliver L, DESMOND Collaborative (2006) Diabetes Education and Self-Management for Ongoing and Newly Diagnosed (DESMOND): process modelling of pilot study. Patient Educ Couns 64:369-377. doi:10.1016/j.pec.2006.04.007 